\title{
IMPAIRMENT E PCLD: CONVERGÊNCIA ENTRE A IFRS 9 E RESOLUÇÃO N. 2.682/99 (BACEN)
}

Ana Lucia Fontes de Souza Vasconcelos

Pós-doutora em Controladoria e Contabilidade pela Faculdade de Economia, Administração e Contabilidade da Universidade de São Paulo (FEAUSP), doutora em Serviço Social pela Universidade Federal de Pernambuco (UFPE) e mestra em Ciências Contábeis e Atuariais pela Pontifícia Universidade Católica de São Paulo (PUC-SP). Professora do Programa de Pós-Graduação em Controladoria e Finanças Empresariais da Universidade Presbiteriana Mackenzie (UPM). E-mail: ana.vasconcelos@mackenzie.br

\section{Mariana do Nascimento Ferreira}

Mestranda em Contabilidade e Controle de Gestão da Faculdade de Economia do Porto da Universidade do Porto, Portugal, e mestra em Controladoria Empresarial pela Universidade Presbiteriana Mackenzie (UPM). 
IMPAIRMENT E PCLD: CONVERGÊNCIA ENTRE A IFRS 9

E RESOLUÇÃO N. 2.682/99 (BACEN)

\section{Octavio Ribeiro de Mendonça Neto}

Doutor em Contabilidade e Atuária pela Faculdade de Economia, Administração e Contabilidade da Universidade de São Paulo (FEAUSP) e mestre em Ciências Contábeis e Atuariais pela Pontifícia Universidade Católica de São Paulo (PUC-SP). Professor do Programa de Pós-Graduação em Controladoria e Finanças Empresariais da Universidade Presbiteriana Mackenzie (UPM).

E-mail: octavio.mendonça@mackenzie.br

\section{RESUMO}

Este artigo apresenta uma comparação entre a IFRS 9 Instrumentos Financeiros (internacional) e a Resolução CMN n. 2.682/99 (Bacen), em relação às perdas por redução do valor recuperável de ativos financeiros. Com o objetivo de propor aos normatizadores um ajuste na norma nacional, a fim de alinhá-la aos padrões internacionais e elaborar argumentos que justifiquem esse alinhamento ou a adoção da IFRS 9 pelo Banco Central do Brasil, foi realizada uma pesquisa exploratória com análise documental das duas normas. O resultado mostrou que ambas estão alinhadas aos padrões e às metodologias de risco estabelecidos pelo Acordo da Basileia e destacou que a IFRS 9 é mais conservadora que a norma local, pois estabelece métodos específicos para classificação e mensuração dos riscos e das perdas, enquanto os critérios vigentes no Brasil são subjetivos, dando às entidades certa liberdade ao desenvolverem seus modelos internos. Um alinhamento atende a diferentes reguladores, melhora o controle e a confiabilidade das informações, e reduz custos e ajustes contábeis.

\section{PALAVRAS-CHAVE}

Convergência. IFRS 9. Impairment. PCLD. Resolução n. 2.682/99. 


\section{INTRODUÇÃO}

Autores como Riahi-Belkaoui (2004) e Deegan e Unerman (2011) afirmam que o processo regulatório da contabilidade foi potencializado pelas crises econômicas ocorridas a partir do século XX, que afetaram investidores nos países onde o mercado de capitais era mais desenvolvido. A crise do subprime de 2008 apontou explicitamente a ocorrência de pressões políticas sobre padrões contábeis mostrando mais evidências de que a regulação contábil tem consequências sociais e econômicas para muitas pessoas e organizações. Um exemplo dessa afirmação é a substituição da International Accounting Standards (IAS) 39 Instrumentos Financeiros - Reconhecimento e Mensuração pela International Financial Reporting Standards (IFRS) 9 Instrumentos Financeiros, que foi acelerada em resposta à pressão exercida pelos países integrantes do Grupo dos 20 (G20) (DEEGAN; UNERMAN, 2011).

A crise financeira de 2008 começou nos Estados Unidos, causada diretamente pela concessão de créditos hipotecários a credores sem capacidade de pagamento, o que resultou no não pagamento dos títulos e na quebra de grandes bancos mundiais. Esse cenário provocou a redução do crédito e dificultou a vida das empresas. A crise trouxe muitos questionamentos sobre a "qualidade" dos padrões estabelecidos na IAS 39, principalmente no tocante ao uso do valor justo e às perdas por redução do valor recuperável (impairment) de ativos financeiros. O modelo existente nessa norma, referente ao impairment, era o de "perda incorrida", em que a perda deverá ser reconhecida a cada balanço quando houver evidência objetiva da sua ocorrência, afetando o fluxo de caixa futuro estimado do ativo financeiro, e estimada com razoável confiança. Inicialmente isso foi projetado pelo International Accounting Standards Board (Iasb), Comitê de Normas Internacionais de Contabilidade, para limitar a entidade de criar reservas ocultas que poderiam ser usadas para melhorar ganhos contábeis em anos ruins. Porém, a crise mostrou que o reconhecimento atrasado das perdas por impairment foi identificado como uma fraqueza nas normas, pois, na essência econômica, as perdas deveriam ser provisionadas quando já existe evidência probabilística de que as perdas esperadas serão maiores.

Em resposta às críticas atribuídas à contabilidade no agravamento da crise, o Iasb emitiu a IFRS 9 Instrumentos Financeiros para substituir a IAS 39. Publicada em 2014, a 
nova norma altera as orientações sobre a classificação e mensuração de ativos financeiros, inclui um novo modelo de provisão para créditos de liquidação duvidosa baseado em perdas esperadas, além de complementar os novos requisitos gerais de contabilidade de hedge publicados em 2013. Tais alterações trarão impacto massivo sobre a forma como instituições financeiras classificam e mensuram as perdas esperadas em suas carteiras de empréstimos e recebíveis.

No Brasil, as instituições financeiras seguem a tabela de ratings especificada na Resolução do Conselho Monetário Nacional (CMN) n. 2.682/99 do Banco Central do Brasil (Bacen) para registrar provisões segundo conceito de perda esperada, o que difere das práticas internacionais estabelecidas pelo IAS 39 que determina o reconhecimento das perdas apenas se houver evidência objetiva de perda incorrida. O padrão contábil brasileiro ainda será adaptado para incluir - total ou parcialmente - as normas da IFRS 9. Normalmente, o Conselho Federal de Contabilidade (CFC) adota os critérios indicados pelo Iasb, mas o mesmo processo de avaliação e adaptação das normas também deverá acontecer com o padrão contábil dos bancos, regulado pelo Bacen, e das seguradoras, regulado pela Superintendência de Seguros Privados (Susep). Os órgãos reguladores devem adotar os padrões internacionais para que as entidades possam aplicá-los. Portanto, o impacto da nova norma no Brasil para os bancos dependerá de como o Bacen vai abordar e “diagnosticar" a IFRS 9, e se irá adotá-la.

Embora não tenha adotado todas as normas internacionais, o Bacen, por meio da Resolução n. 3.786/2009, requer que as instituições financeiras elaborem e divulguem anualmente suas demonstrações contábeis consolidadas com base no padrão contábil internacional emitido pelo Iasb, ou seja, as instituições financeiras são obrigadas a apresentar duas demonstrações: uma no padrão nacional, emitido pelo Bacen, e outra no padrão internacional, emitido pelo Iasb. Consequentemente, a divergência entre as normas faz com que as instituições financeiras percam em custo-benefício no momento de elaborar as suas demonstrações financeiras, pois precisam produzir informações diferentes partindo de uma única base, manter diversos controles, realizar cálculos diferentes, investir em processos onerosos e morosos, e realizar ajustes contábeis para que possam atender a diferentes reguladores. Diante do exposto, esta pesquisa tem por objetivo ana- 
lisar a convergência entre a nova norma IFRS 9 Instrumentos Financeiros e a Resolução n. 2.682/99, no que se refere a valor recuperável dos ativos, a fim de identificar argumentos que defendam o alinhamento entre elas.

A principal contribuição teórica deste estudo é mapear e diagnosticar a convergência entre a norma internacional IFRS 9 Instrumentos Financeiros e a norma nacional da Resolução n. 2.682/99, e elaborar um relatório argumentativo que possa ser usado para pleitear, no Bacen, um ajuste nessa resolução, a fim de alinhá-la à nova norma internacional, contribuindo de forma prática para futuras mudanças ou edições de normas que aumentem a eficiência do sistema financeiro e o aprimoramento de suas demonstrações contábeis.

\section{FUNDAMENTAÇÃO TEÓRICA}

\section{Teoria da regulação}

O contexto do nascimento da teoria da regulação foi marcado pelo surgimento de uma crise econômica, em que se assistiu a uma ruptura do crescimento econômico observado nos anos 1960. Cascione (2011) destaca que as crises foram objeto-chave no estudo dos regulacionistas. Há, na história econômica do capitalismo, um número incontável de crises, variando em intensidade, espaço e tempo, desde as menores até as grandes crises mundiais, como as de 1929, dos anos 1970 e de 2008. De acordo com alguns autores, essas crises foram causadas pela superprodução, pelo desequilíbrio entre produção e demanda, pelos excessos creditícios etc. Há também aqueles que se distanciam das causas específicas e enxergam as crises como parte do capitalismo ou relacionadas a ele de forma intrínseca e necessária.

É possível notar uma correlação entre crise e crédito, e muitos autores creem que seja o excesso do crédito o verdadeiro causador das crises econômicas. Para Mises (2002), a crise surge no desequilíbrio entre produção e consumo, incendiada por um problema monetário, quando as grandes instituições financeiras emprestadoras exageram na dose do crédito. 
A teoria da regulação baseia-se na análise das relações sociais subjacentes à acumulação e reprodução do capital.

E nessa acumulação e reprodução do capital exercem as instituições financeiras papel central e fundamental para o pleno funcionamento do sistema capitalista. Como grupo dominante que são, pois se estabelece já na relação creditícia ou mesmo antes que ela ocorra uma relação de domínio - ao terem o privilégio de impor suas condições ou de estabelecer juros elevados (decorrente da permanente escassez da moeda e do crédito) logo se aliam ao Estado e coordenam com ele uma estratégia de hegemonia capitalista. Obviamente que seria impossível a manutenção de uma estratégia hegemônica sem a lei (CASCIONE, 2011, p. 6).

Na crise de 2008, a exemplo de todas as outras anteriores, os preços de determinados ativos, anos antes da eclosão, principalmente os de imóveis, elevaram-se consistentemente, o que incentivou as instituições financeiras a conceder crédito tendo por base a geração de caixa desses ativos ou acreditando, quando os recebiam em garantia, que sua venda forçada teria valor suficiente para pagar seus empréstimos. Portanto, em tempos de crise, as instituições financeiras merecem atenção especial, pois trabalham alavancadas e, como tomam emprestado (normalmente no curto prazo) para emprestar (normalmente em prazo maior), passam a enfrentar problemas com os pagamentos de suas obrigações.

Como o sistema financeiro está interligado em redes pela concessão de créditos recíprocos temos então o mais grave risco para a economia de um país, e dependendo de suas proporções para a economia mundial (vide a quebra de bancos nos Estados Unidos da América durante o segundo semestre de 2008), o chamado risco sistêmico, ou o risco de quebra de várias instituições financeiras seguidas e dependentes de crédito entre si (CASCIONE, 2011, p. 35). 


\section{Teorias da regulação e a contabilidade}

De acordo com Baldwin e Cave (1999, p. 63), “a regulação pode ser empreendida por uma variedade de órgãos e a natureza das instituições pode afetar não somente o estilo da regulação e as estratégias empregadas, mas também o sucesso das intenções regulatórias". Os autores afirmam que regulamentação é, com frequência, associada a uma atividade que restringe ou previne a ocorrência de certos comportamentos indesejados, limitando a liberdade dos agentes.

Diversas teorias surgiram para explicar a regulação e mostrar como ela aparece, se desenvolve e declina. Essas teorias podem ser meramente descritivas dos fenômenos regulatórios, prescritivas de como deve ser organizado o processo de regulação ou uma combinação das duas perspectivas (CARDOSO et al., 2009). Neste trabalho, serão abordadas algumas das diversas teorias sobre regulação, que ajudarão a compreender a regulação da contabilidade.

\section{Teoria do interesse público}

Essa teoria baseia-se no feito de que a regulação existe para resolver falhas de mercado, tais como monopólios, externalidades negativas e assimetria informacional. Admite que o regulador sempre visa maximizar o bem-estar da sociedade e age sempre nos melhores interesses para isso, buscando remediar as falhas onde os mecanismos do próprio mercado não forem suficientes para resolvê-las (BALLEISEN; MOSS, 2010).

O propósito dessa abordagem é atingir certos resultados desejados pela comunidade que o mercado não teria condições de facilitar. A intervenção do Estado na economia, atuando para combater as falhas de mercado, é também um instrumento para assegurar uma maior estabilidade diante dos inevitáveis ciclos econômicos, atenuando os efeitos dos períodos negativos - uma ideia que é amplamente difundida desde o impacto da Grande Depressão (HERBST; DUARTE, 2013, p. 26). 


\section{Teoria da captura}

De acordo com essa teoria, a regulação sempre é criada em benefício das entidades reguladas. A teoria da captura surgiu como contraponto à teoria do interesse público, uma vez que diversas evidências empíricas apresentam provas de que a regulação fora exercida em prol da empresa regulada e, consequentemente, em detrimento da sociedade (CARDOSO et al., 2009).

Beaver (1998, p.164) explica a teoria da captura: "o principal beneficiário da regulação não é o público (ou investidores, no caso da Lei das Sociedades por Ações), mas aqueles que são regulados”. Viscusi, Vernon e Harrington Jr. (2005, p. 379-380) afirmam que, segundo a teoria da captura, a regulação é oferecida como resposta à demanda da indústria por regulação, de forma que "os legisladores são capturados pela indústria”, ou a agência reguladora se torna controlada pela indústria com o passar do tempo, isto é, “os reguladores são capturados pela indústria”.

\section{Teoria da competição entre os grupos de interesse}

Também chamada de teoria econômica da regulação, baseia-se na premissa de que o poder do regulador pode ser usado para beneficiar grupos ou indivíduos particulares, ou seja, a regulação é fruto da pressão exercida por grupos de influência nos processos de normatização. Nessa teoria, o legislador e o regulador estão preocupados em se perpetuar no poder. Portanto, a regulação é desenhada para atender às necessidades do grupo de interesse que exerce maior pressão relativa sobre o regulador e o legislador (CARDOSO et al., 2009).

Tandy e Wilburn (1996) identificaram cinco categorias de interesses, especificamente para a regulação contábil sob o enfoque da teoria da competição entre grupos de interesses: normatizadores e associações profissionais ligadas à contabilidade; empresas de auditoria; outras empresas e associações de empresas; acadêmicos; e outros participantes.

Uma pesquisa realizada por Tavares, Anjos e Paulo (2014) demonstrou empiricamente que o processo de regulação das práticas contábeis não é neutro e apresenta 
vieses de interesses de agentes econômicos que podem afetar a decisão final do normatizador. A pesquisa constatou que os requisitos iniciais dos normatizadores aproximam-se dos argumentos da teoria do interesse público, mas acabam sendo contrariados pelos incentivos das firmas, relacionados com a teoria da competição entre grupos de interesses. Assim, é perceptível que setores específicos se posicionam de forma convergente na busca pelos seus interesses, com o intuito de conduzir o normatizador para suas posições.

Dentre as teorias apresentadas, a teoria da competição entre os grupos de interesse está mais alinhada ao presente trabalho, cujo objetivo é elaborar argumentos que auxiliem as instituições financeiras no processo de lobbying junto ao regulador (Bacen), em relação à possível adequação da Resolução n. 2.682/99 aos requisitos da IFRS 9.

\section{Regulação contábil e convergência dos padrões}

Como exposto anteriormente, autores afirmam que o processo regulatório da contabilidade, do sistema financeiro e de outros foi potencializado pelas crises econômicas ocorridas a partir do século XX. Com base nisso,

[...] é possível afirmar que o início do processo regulatório na contabilidade foi consequência do cenário econômico da época e, portanto, encontra sua raiz teórica atrelada às teorias desenvolvidas no âmbito da economia que procuraram explicar as razões pelas quais deveria ocorrer a intervenção do Estado no mercado e o comportamento do regulador frente aos diversos incentivos advindos dos grupos de interesses (TAVARES; ANJOS; PAULO, 2014, p. 46).

Silva (2007) pondera que, por causa da grande variedade de usuários e de interesses nas informações contábeis, cada país desenvolveu um processo peculiar de elaboração de suas normas contábeis. Com a finalidade de harmonizar a contabilidade no contexto internacional e promover a convergência entre normas contábeis locais e internacionais, foi criado, em 1973, o International Accounting Standards Committee (Iasc), substituído em 
2001 pelo Iasb, que assumiu suas responsabilidades. O processo de regulação contábil ganhou força com a parceria entre o Iasb e o Financial Accounting Standards Board (Fasb) a partir de 2002, cujo objetivo é elaborar e emitir normas internacionais que diminuam as diferenças nas práticas contábeis e alinhe um mesmo padrão.

No Brasil, a harmonização entre os padrões contábeis foi iniciada com o surgimento do Comitê de Pronunciamentos Contábeis (CPC), a partir da Resolução n. 1.055/2005 do CFC. O início do processo se deu com a entrada em vigor da Lei n. 11.638/2007 que previa a adoção de um novo modelo de regulação contábil e resultou na emissão de pronunciamentos técnicos pelo CPC, aderentes aos novos padrões internacionais emitidos pelo Iasb (OLIVEIRA; COSTA JÚNIOR; SILVA, 2013).

\section{Regulação contábil para perda do valor recuperável de ativos}

A função da provisão para crédito de liquidação duvidosa (PCLD) é espelhar no resultado contábil das instituições as prováveis perdas decorrentes de insolvência em sua carteira de crédito. Também pode ser usada como ferramenta administrativa, pois demonstra a qualidade da carteira e fornece bons indícios para avaliação das políticas de crédito vigentes. O Bacen tem determinações específicas quanto à PCLD, regulamentadas na Resolução n. 2.682/99, que determina a classificação dos créditos concedidos de acordo com o risco das operações e o tempo de atraso, considerando o histórico do cliente, sua capacidade como tomador de empréstimos no mercado e sua capacidade de pagamento futura, além do setor de atividade econômica, do limite de crédito, da natureza da operação e das garantias.

$\mathrm{O}$ artigo $1^{\circ}$ da Resolução n. 2.682/99 determina que as instituições financeiras e as demais instituições autorizadas a funcionar pelo Bacen devem classificar as operações de crédito em ordem crescente de risco, conforme os níveis apresentados na Tabela 1. Além da classificação da operação no nível de risco adequado, é de responsabilidade da instituição verificar a consistência das informações e outros aspectos internos e externos para negociação, a fim de manter a solidez da carteira de crédito, tais como: 
- Em relação ao devedor e aos seus garantidores: situação econômico-financeira; grau de endividamento; capacidade de geração de resultados; fluxo de caixa; pontualidade nos pagamentos; contingências; setor de atividade econômica; e limite de crédito.

- Em relação à operação: a natureza e finalidade da transação, e características das garantias, particularmente quanto à suficiência, à liquidez e ao valor.

Tais aspectos subsidiam a decisão de conceder ou não o crédito e contribuem para a apuração e diferenciação do nível de risco desses créditos. Entretanto, a norma estabelece que os bancos devem avaliar o risco do tomador de crédito, mas não determina como esses fatores devem ser combinados. Cabe aos bancos a responsabilidade de avaliar e ponderar cada um desses elementos, desde que "com base em critérios consistentes e verificáveis" (artigo 20 da Resolução n. 2.682/99), a fim de apurar o risco de seus créditos.

Segundo Verrone (2007), a Resolução n. 2.682/99 introduziu uma certa liberdade para que as instituições financeiras pudessem modelar o risco, o que representou uma importante inovação nas normas de crédito brasileiras, que eram prescritivas e descritivas sobre o que poderia ou não ser realizado, sobre como deveria ser sua execução e sobre o procedimento a ser adotado em cada possível situação. Apesar da abordagem aberta e flexível da norma, a delegação de poder ao mercado não foi completa, pois o CMN determina algumas linhas gerais da sistemática de classificação de risco, como avaliação dos riscos do devedor e o risco da operação, aponta quesitos mínimos que devem ser considerados para esses itens e estabelece prazos para a revisão periódica das classificações, o provisionamento em função de atrasos e outros procedimentos, cuja função é moderar a liberdade delegada às instituições financeiras.

A PCLD deve ser constituída com base em critérios consistentes e verificáveis:

- Sistemática de provisionamento: trata-se do primeiro elemento moderador presente na resolução. $\mathrm{O}$ artigo $6^{\circ}$ da norma prevê que, para o total de operações classificadas em determinado nível de risco, deve ser constituído um percentual de provisão (Tabela 1). 
TABELA 1 - Critérios de provisão do Banco Central

\begin{tabular}{cc}
\hline Nível de risco & Provisão constituída \\
\hline AA & $0,00 \%$ \\
\hline A & $0,50 \%$ \\
\hline B & $1,00 \%$ \\
\hline C & $3,00 \%$ \\
\hline D & $10,00 \%$ \\
\hline E & $30,00 \%$ \\
\hline F & $50,00 \%$ \\
\hline G & $70,00 \%$ \\
\hline H & $100,00 \%$
\end{tabular}

Fonte: Elaborada pelos autores com base na análise da Resolução n. 2.682/99.

Do ponto de vista contábil, a provisão destina-se à cobertura de perdas prováveis, tendo um caráter estimativo, e deve ser constituída mensalmente, não podendo ser inferior ao somatório decorrente da aplicação dos percentuais apresentados na Tabela 1. Apesar de terem sido determinados nove níveis de risco com faixas específicas de provisionamento, as instituições financeiras, se considerarem necessário um adequado gerenciamento de sua carteira, não encontrarão impedimento na norma para que utilizem internamente níveis adicionais de risco, subdividindo aqueles predefinidos.

- Prazo de inadimplência: trata-se do segundo elemento moderador referente à liberdade de as instituições financeiras modelarem seus riscos de crédito para fins regulatórios. $\mathrm{O}$ artigo $4^{\circ}$ da norma estabelece a classificação mínima admitida para créditos que se apresentem em atraso. Conforme Tabela 2, o prazo de inadimplência é o que classifica o cliente em um determinado nível de risco. 
TABela 2 - Critérios de prazos de inadimplência do Banco Central

\begin{tabular}{cc}
\hline Dias de atraso & Nível de risco \\
\hline 0 & AA \\
\hline 0 & A \\
\hline 15 e 30 dias & C \\
\hline 31 e 60 dias & D \\
\hline 61 e 90 dias & E \\
\hline 91 e 120 dias & F \\
\hline 121 e 150 dias & G \\
\hline 151 e 180 dias & H \\
\hline 151 e 180 dias &
\end{tabular}

Fonte: Elaborada pelos autores com base na análise da Resolução n. 2.682/99.

O artigo $4^{\circ}$ da resolução também determina que a classificação da operação nos níveis de risco, de que trata o artigo $1^{\circ}$, deve ser revista, no mínimo:

- mensalmente, por ocasião dos balancetes e balanços, em função de atraso verificado no pagamento de parcela de principal ou de encargos;

- semestralmente, para operações de um mesmo cliente ou grupo econômico cujo montante seja superior a $5 \%$ do patrimônio líquido ajustado;

- anualmente, em todas as situações, exceto na hipótese prevista no artigo $5^{\circ}$.

- Possibilidade de ação do órgão de supervisão: o terceiro elemento que permite corrigir eventuais desvios é a intervenção direta do órgão de supervisão, ao qual se concedem algumas prerrogativas descritas no artigo $13^{\circ}$ da Resolução n. 2.682/99, ou seja, o Bacen poderá baixar normas complementares necessárias ao cumprimento da resolução, bem como determinar: a reclassificação de operações; o provisionamento adicional; as providências saneadoras a serem adotadas pelas instituições, com vistas a assegurar a sua liquidez e adequada estrutura patrimonial; a alteração dos critérios de classificação de créditos, de contabilização e de constituição de provisão; o teor das 
informações e notas explicativas constantes das demonstrações financeiras; os procedimentos e controles a serem adotados pelas instituições.

Para Verrone (2007), a previsão normativa de impor a alteração de critérios de classificação representa a possível recusa pelo Bacen dos critérios adotados pela instituição financeira, ou seja, uma invalidação do modelo que pode levar à substituição parcial ou total. Portanto, se o órgão de supervisão, durante seu processo de fiscalização em risco de crédito, não apontar problemas ou correções a serem efetuadas na sistemática de classificação de uma determinada instituição, tem-se de fato uma validação do modelo adotado.

\section{Resolução n. 2.682/99 e a abordagem Internal Ratings Based (IRB) para risco de crédito do Acordo da Basileia II}

A abordagem IRB, para o risco de crédito, utiliza um modelo estatístico para mensurar as perdas esperadas que podem ocorrer no horizonte de um ano. O objetivo é que as provisões de um banco sejam suficientes para suportar as perdas esperadas durante os próximos 12 meses. A apuração do requerimento de capital deverá considerar os seguintes componentes de risco:

- Probability default (PD): possibilidade de um determinado cliente ficar inadimplente. Deve considerar as características do cliente e está associada ao risco do cliente (rating) apresentado na análise de cliente (ANC).

- Loss given default (LGD): medida preditiva que informa o quanto efetivamente não é recuperado quando um cliente entra em inadimplência. $\mathrm{Na}$ apuração dessa medida, deve ser considerada a estimativa de quanto se recupera de uma dívida em atraso menos os custos no processo de recuperação.

- Exposure at default (EAD) ou exposição no momento da inadimplência: considerando que um cliente tende a aumentar seu endividamento ao se aproximar de uma situação em que não terá capacidade de honrar seus compromissos, esse componente evidencia o montante (efetivo + potencial) do endividamento do cliente no momento da inadimplência. 
- Effective maturity (M) ou maturidade efetiva: prazo até o vencimento da operação, podendo ser ajustado em função do fluxo de caixa ou de critérios do regulador.

Conforme trabalho apresentado por Watanabe (2006), os procedimentos para a estimativa das perdas esperadas diferem daqueles determinados pela Resolução n. 2.682/99. As diferenças encontradas são apresentadas no Quadro 1.

QUADRO 1 - Comparações entre Basileia II e a Resolução n. 2.682/99

\begin{tabular}{|c|c|c|}
\hline & Basileia II - IRB & Resolução n. 2.682/99 \\
\hline Modelo & $\begin{array}{l}\text { Modelo estatístico para determinar } \\
\text { as perdas esperadas }\end{array}$ & $\begin{array}{l}\text { Modelo de classificação das operações de crédito } \\
\text { por níveis de risco }\end{array}$ \\
\hline Objetivo & $\begin{array}{l}\text { Garantir que as provisões } \\
\text { sejam iguais ou superiores } \\
\text { às perdas esperadas }\end{array}$ & $\begin{array}{l}\text { Garantir que as provisões sejam constituídas de } \\
\text { acordo com a classificação por níveis de risco da } \\
\text { operação de crédito }\end{array}$ \\
\hline Cálculo & $\begin{array}{l}\text { Perdas esperadas }(\mathrm{EL}) \text { nos } \\
\text { próximos } 12 \text { meses }\end{array}$ & $\begin{array}{l}\text { Provisões - quanto pior a classificação, maior a } \\
\text { provisão }\end{array}$ \\
\hline Parâmetros & PD, LGD, EAD e M & Devedor, garantidor e operação \\
\hline Indícios & Inadimplência & Classificação da operação e/ou atraso \\
\hline Fórmula & $\mathrm{EL}=\mathrm{PD} \times \mathrm{LGD} \times \mathrm{EAD}$ & $\begin{array}{l}\text { Provisão = valor contábil x percentual, conforme } \\
\text { o nível de risco da operação }\end{array}$ \\
\hline
\end{tabular}

Fonte: Resolução n. 2.682/99 e normas do Acordo da Basileia.

- A classificação por faixas de risco pela Basileia II é efetuada utilizando dados quantitativos e qualitativos do cliente em risco. Na resolução do CMN, a classificação é feita de acordo com a operação, utilizando dados do cliente e dos garantidores

- De acordo com a resolução do CMN, após 15 dias de atraso, há a necessidade de constituir provisão para aquela operação de crédito. Já para a Basileia II, somente após 90 dias de atraso, o cliente é considerado inadimplente.

- A Basileia II utiliza a LGD, que é um percentual estimado dos valores que o banco não espera receber mais os custos relacionados ao não recebimento. Há uma LGD para 
cada tipo de operação. A resolução do CMN utiliza uma tabela de atraso com percentual estabelecido.

- As probabilidades de inadimplência (PD) são estimadas para cada faixa de risco de cliente, com base em dados históricos. Dessa forma, para cada faixa de risco, há uma $\mathrm{PD}$, enquanto na resolução do $\mathrm{CMN}$ o percentual de provisão é determinado pela norma.

- O cálculo das perdas esperadas utiliza o valor estimado no momento da inadimplência, enquanto a resolução do CMN determina que seja utilizado o valor contábil.

Com tal comparação, é possível destacar que os critérios da Basileia em relação aos riscos de crédito são mais abrangentes e objetivos, dando às instituições critérios específicos para a elaboração de seus modelos internos, enquanto a resolução do Bacen apresenta critérios subjetivos, deixando que as instituições tenham mais liberdade para desenvolver seus modelos internos. Apesar de ter seus critérios, o Bacen também regulamenta que as instituições financeiras obedeçam aos aspectos da Basileia por meio da Resolução n. 4.193/2013 e da Circular n. 3.648/2013, que estabelecem os requisitos mínimos para o cálculo da parcela relativa às exposições ao risco de crédito sujeito ao cálculo do requerimento de capital mediante sistemas internos de classificação do risco de crédito (abordagens IRB).

\section{Basileia III}

Em resposta à crise financeira internacional ocorrida em 2008 e visando à evolução do Acordo da Basileia, em junho de 2011, foi publicado o documento Basel III: a global regulatory framework for more resilient banks and banking systems - revised, também conhecido como Basileia III. O novo acordo tem como objetivo ampliar a capacidade do setor bancário em absorver choques derivados de problemas econômicos ou financeiros e, assim, reduzir o risco de transbordamento de eventuais problemas do setor financeiro para o setor real da economia. É importante destacar que as bases da nova regulação bancária se mantiveram atreladas à Basileia II. Contudo, mudanças relevantes foram introduzidas nesse arcabouço para que a reforma fosse capaz de atingir o objetivo traçado. Como veremos adiante, as metodologias definidas pelo Acordo da Basileia em relação à 
previsão de risco de crédito é o ponto que aproxima as normas estudadas no trabalho. As principais linhas de mudança introduzidas pela Basileia III foram:

- A reformulação da estrutura de capital das instituições financeiras, dividida, por sua vez, entre: 1. o aprimoramento do cálculo do ativo ponderado pelo risco; 2. a ampliação dos requerimentos de capital; e 3. a redefinição do capital regulamentar e seus níveis.

- A introdução dos índices de liquidez e do índice de alavancagem.

\section{A provisão para créditos de liquidação duvidosa segundo a IFRS}

Em conformidade com a nova norma, as perdas esperadas em ativos financeiros formam a base para a determinação das perdas a serem reconhecidas no resultado, em decorrência da perda do valor recuperável dos ativos financeiros. Para aplicar o princípio da "perda esperada", a norma descreve os componentes-chave da estimativa das provisões para perdas esperadas nos ativos financeiros:

- Identificar toda a informação razoável, suportável e relevante para formar a estimativa de perda para o futuro.

- Identificar a gama de possíveis resultados considerando a probabilidade e razoabilidade desses resultados (por exemplo, uma gama de resultados possíveis pode incluir um mínimo de dois resultados ponderados por probabilidade, mas o uso de um único resultado mais provável não seria apropriado).

- O valor do dinheiro no tempo.

Em linhas gerais, o modelo de perdas de crédito esperadas usa uma abordagem de mensuração dupla. Se o risco de crédito de um ativo financeiro não tiver aumentado significativamente desde seu reconhecimento inicial, o ativo financeiro terá uma provisão para perdas esperadas para 12 meses. Se o risco de crédito tiver aumentado significativamente, a provisão será para as perdas esperadas durante toda a vida do instrumento, aumentando a provisão de impairment. Entretanto, a norma não define o que é “significante", portanto será necessário julgamento para determinar se o ativo deve ser transferido entre essas categorias. 
O novo modelo será aplicável a ativos financeiros que são: instrumentos de dívida reconhecidos no balanço, como empréstimos e bonds; classificados como mensurados a valor justo; e certos compromissos de empréstimos e garantias financeiras. Os novos requerimentos para impairment de ativos financeiros passaram a ser baseados no modelo de perda esperada, e alguns dos principais conceitos são apresentados a seguir:

- Impairment de ativos financeiros: o principal objetivo dos requerimentos de impairment é reconhecer as expectativas de perdas de crédito expected credit (ECL) para toda vida útil dos ativos financeiros que tiverem um aumento significativo no risco de crédito, desde o seu reconhecimento inicial - em base individual ou coletiva -, considerando todas as informações razoáveis e suportáveis, incluindo o que é prospectivo.

- Fluxo de aplicação: para a aplicação dos requerimentos de impairment segundo a IFRS 9, a entidade deve seguir o fluxo apresentado na Figura 1.

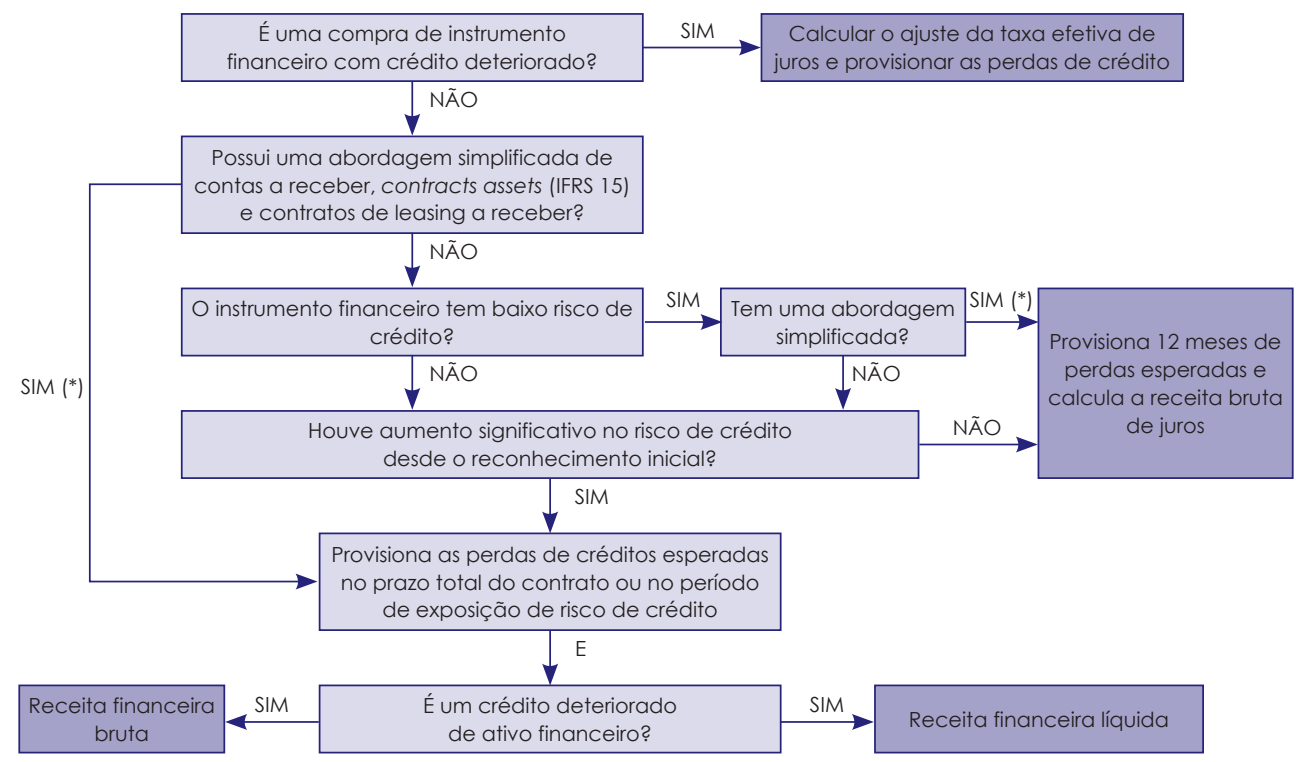

FIGURA 1 - Fluxograma da aplicação de impairment segundo a IFRS 9

${ }^{*}$ ) A abordagem simplificada é opcional, e pode ser aplicada para contratos de arrendamento mercantil e contratos a receber com prazos de 12 meses (ou menos) e baixo risco de crédito.

Fonte: Elaborada pelos autores com base na análise da IFRS 9. 
- Abordagem geral: para cada data de balanço, a entidade deve reconhecer uma provisão de perda baseada nos estágios apresentados no fluxograma da Figura 2.

Mudança na qualidade de crédito desde o reconhecimento inicial

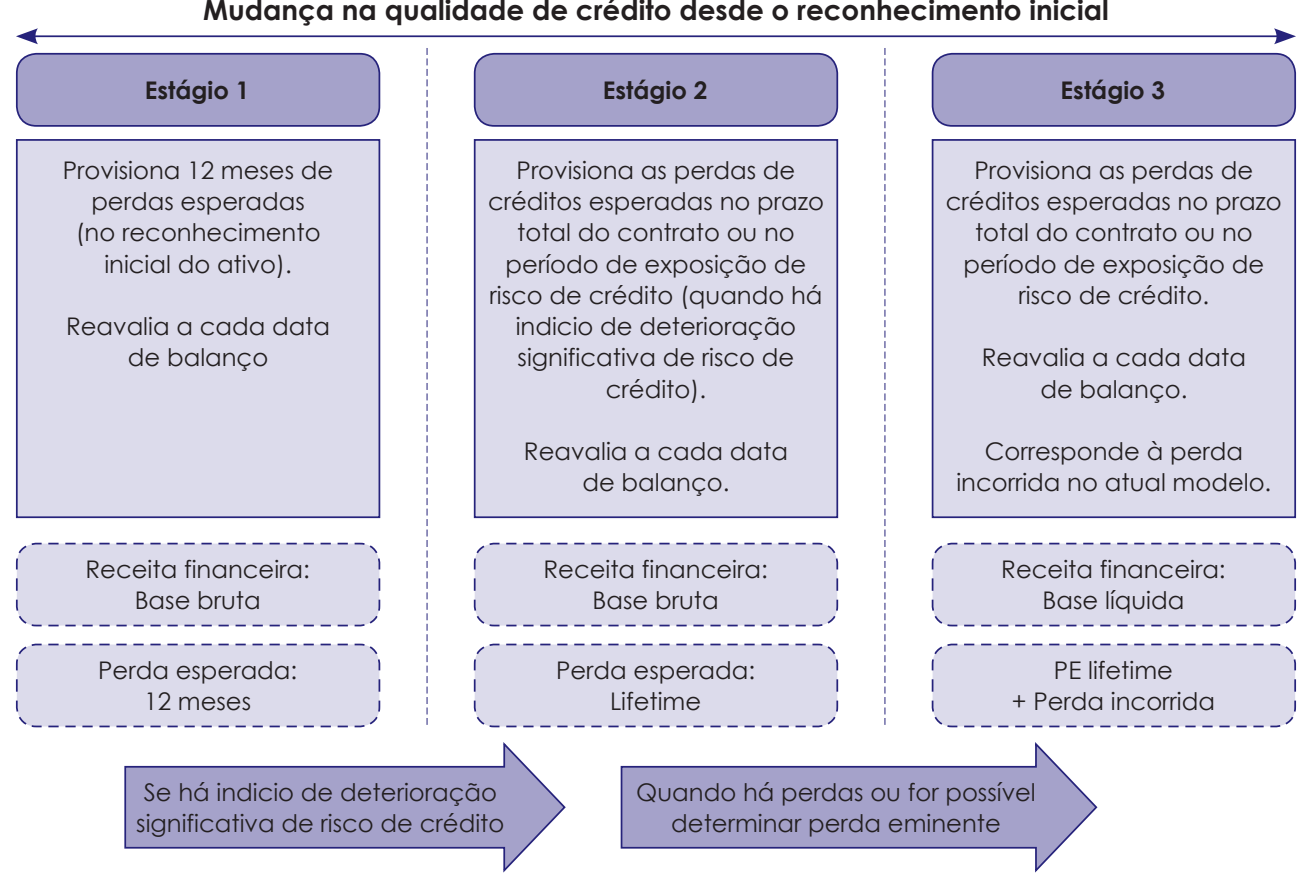

FIGURA 2 - Fluxograma de estágios de mudanças na qualidade de crédito

Fonte: Elaborada pelos autores com base na IFRS 9.

- Estágio 1 - sem aumento no risco de crédito: todos os novos empréstimos são automaticamente categorizados nesse estágio.

- Estágio 2 - indícios de risco de crédito, exemplos: mudanças significativas nos indicadores de preço interno; mudanças significativas nos indicadores de risco de crédito do mercado; downgrade de rating de crédito interno e externo; mudanças adversas de forecast nos negócios, nas finanças ou nas condições econômicas que possivelmente impediriam os clientes de pagar os empréstimos; mudanças significativas nos valores de garantias que suportam as obrigações; mudanças significativas no gerenciamento de risco de crédito dos clientes; informações de atraso de pagamentos. 
- Estágio 3 - evidência de impairment: empréstimos são categorizados nesse estágio quando há uma perda efetiva.

- Mensuração: define-se como perda de crédito a diferença entre os fluxos de caixa contratuais devidos a uma entidade e todos os fluxos de caixa que a entidade espera receber, descontados a taxa de juros efetiva original ou a taxa de juros efetiva ajustada ao crédito para ativos com problemas de recuperação de crédito:

\section{PERDA DE CRÉDITO = FLUXO DE CAIXA DEVIDO - (FLUXO DE CAIXA A RECEBER $x$ TAXA EFETIVA DE JUROS ${ }^{1}$ )}

A norma não descreve uma abordagem específica para estimar as perdas de crédito, mas enfatiza que deve refletir:

1) Um valor não tendencioso e provável.

2) O valor do dinheiro no tempo.

3) Informações razoáveis e sustentáveis, disponíveis sem custo ou esforço elevados na data de relatório, sobre eventos passados, condições atuais e previsões de condições econômicas futuras.

- Perdas esperadas de lifetime: possíveis eventos de perda de crédito para toda vida útil de um instrumento financeiro. A expectativa de perda de crédito deve ser baseada nos fluxos de caixa a receber previstos em contrato ou nos fluxos de caixa a receber expostos ao risco de crédito.

- Probabilidade ponderada de perda: as estimativas de perdas de crédito mensuradas para a vida de um instrumento financeiro devem identificar o valor e tempo dos fluxos de caixa para resultados específicos e probabilidade estimada desses resultados.

\footnotetext{
1 Ao calcular a taxa de juros efetiva, a entidade estimará os fluxos de caixa esperados levando em consideração todos os termos contratuais do instrumento financeiro, mas não considerará perdas de crédito esperadas.
} 
Embora uma entidade não precise identificar todos os possíveis cenários, deverá considerar a possibilidade de a perda de crédito ocorrer, mesmo que a probabilidade seja baixa.

\section{Diferenças metodológicas entre IFRS 9 e Basileia III no cálculo de impairment}

A comparação entre as metodologias nos leva a perceber que a nova norma está mais conservadora e apresenta maior alinhamento com os critérios mundialmente aceitos pelo Acordo da Basileia. O Quadro 2 apresenta a comparação entre as metodologias.

QUADRO 2 - Diferenças metodológicas entre IFRS 9 e Basileia III

\begin{tabular}{|c|c|c|}
\hline Parâmetros & Basileia III & IFRS 9 \\
\hline \multicolumn{3}{|l|}{ PDs } \\
\hline Estimativa & $\begin{array}{l}\text { Estimativa média de perda nos próximos } \\
12 \text { meses }\end{array}$ & $\begin{array}{l}\text { Estimativa de } 12 \text { meses ou prazo de vida } \\
\text { útil dependendo da qualidade do crédito }\end{array}$ \\
\hline $\begin{array}{l}\text { Período de } \\
\text { mensuração }\end{array}$ & $\begin{array}{l}\text { Média histórica ao longo do ciclo } \\
\text { econômico inteiro }\end{array}$ & Reflete ciclos econômicos atuais e futuros \\
\hline \multicolumn{3}{|l|}{ LGDs } \\
\hline Estimativa & Estimativa média do valor de perda & Estimativa do valor de perda \\
\hline $\begin{array}{l}\text { Tratamento de } \\
\text { despesas de } \\
\text { cobrança }\end{array}$ & $\begin{array}{l}\text { Recuperações líquidas de despesas de } \\
\text { cobrança diretas e indiretas }\end{array}$ & $\begin{array}{l}\text { Recuperações líquidas de despesas de } \\
\text { cobrança diretas apenas }\end{array}$ \\
\hline $\begin{array}{l}\text { Período de } \\
\text { mensuração }\end{array}$ & $\begin{array}{l}\text { Reflete o período de maior perda de } \\
\text { crédito }\end{array}$ & Reflete ciclos econômicos atuais e futuros \\
\hline \multicolumn{3}{|l|}{ EL } \\
\hline $\begin{array}{l}\text { Base de } \\
\text { exposição }\end{array}$ & $\begin{array}{l}\text { Baseado na EAD e inclui serviços } \\
\text { inutilizados e contingentes }\end{array}$ & $\begin{array}{l}\text { Baseado na EAD e inclui serviços } \\
\text { inutilizados e contingentes }\end{array}$ \\
\hline
\end{tabular}

Fonte: Elaborado pelos autores com base em análise das normas IFRS 9 e Basileia III. 


\section{METODOLOGIA}

O produto final desta pesquisa é um relatório de argumentações que será utilizado para pleitear ao Bacen o ajuste da Resolução n. 2.682/99 em convergência com a nova norma internacional IFRS 9. Para tanto, quanto aos objetivos, foi realizada uma pesquisa exploratória. De acordo com Beuren e Raupp (2003), por meio do estudo exploratório, busca-se conhecer o assunto com maior profundidade, visando torná-lo mais claro ou construir questões importantes para conduzir a pesquisa. Ademais, explorar pressupõe a busca de novas dimensões. Nesse sentido, Beuren e Raupp (2003) destacam que, para Gil (1999), esse tipo de pesquisa deverá ser escolhido quando o assunto é pouco explorado.

Quanto aos procedimentos, foi realizada uma pesquisa documental, que, de acordo com Martins e Theóphilo (2009), tem como característica utilizar documentos como fonte de dados, informações e evidências. Assim, foram utilizadas, para análise e discussão, as normas relacionadas ao valor recuperável dos ativos no Brasil e no âmbito internacional.

\section{Relatório de argumentações}

A comparação entre as normas está apresentada no Quadro 3.

QUADRO 3 - Comparativo entre Resolução n. 2.682/99, IFRS 9 e Basileia

\begin{tabular}{|c|c|c|c|}
\hline & Resolução n. 2.682/99 & IFRS 9 impairment & Basileia \\
\hline Mensuração & $\begin{array}{l}\text { Percentual de perdas } \\
\text { esperadas baseado no atraso } \\
\text { no pagamento de parcela de } \\
\text { principal ou de encargos. } \\
\text { a) } 0-15 \text { dias - } 0,5 \% \\
\text { b) } 15-30 \text { dias - } 1 \% \\
\text { c) } 31-60 \text { dias }-3 \% \\
\text { d) } 61-90 \text { dias }-10 \% \\
\text { e) } 91-120 \text { dias - } 30 \% \\
\text { f) } 121-150 \text { dias }-50 \% \\
\text { g) } 151-180 \text { dias }-70 \% \\
\text { h) }>180 \text { dias }-100 \%\end{array}$ & $\begin{array}{l}\text { A perda de crédito é a } \\
\text { diferença entre os fluxos } \\
\text { de caixa contratuais que } \\
\text { são devidos à entidade e } \\
\text { os fluxos de caixa que a } \\
\text { entidade estima receber } \\
\text { descontados a taxa de } \\
\text { juros efetiva original (ou } \\
\text { ajustado). } \\
\text { Lifetime ECL. } \\
\text { Estimativas prospectivas. }\end{array}$ & $\begin{array}{l}\text { Não há percentuais } \\
\text { predefinidos, porém as } \\
\text { estimativas devem ser } \\
\text { realizadas de acordo com } \\
\text { as metodologias de } \\
\text { avaliação do risco de } \\
\text { crédito - ou risco de } \\
\text { perdas com } \\
\text { inadimplências. }\end{array}$ \\
\hline
\end{tabular}


QUADRO 3 - Comparativo entre Resolução n. 2.682/99, IFRS 9 e Basileia

\begin{tabular}{|c|c|c|c|}
\hline & Resolução n. 2.682/99 & IFRS 9 impairment & Basileia \\
\hline 更 & $\begin{array}{l}\text { Classificação por height, } \\
\text { baseado no atraso no } \\
\text { pagamento de parcela de } \\
\text { principal ou de encargos. } \\
\text { a) } 0-15 \text { dias } \\
\text { b) } 15-30 \text { dias } \\
\text { c) } 31-60 \text { dias } \\
\text { d) } 61-90 \text { dias } \\
\text { e) } 91-120 \text { dias } \\
\text { f) } 121-150 \text { dias } \\
\text { g) } 151-180 \text { dias } \\
\text { h) }>180 \text { dias }\end{array}$ & $\begin{array}{l}\text { O risco de crédito - ou } \\
\text { risco de perdas com } \\
\text { inadimplências - deve ser } \\
\text { avaliado por meio de três } \\
\text { componentes estatísticos: } \\
\text { - PD: estimativa de } 12 \\
\text { meses ou prazo de vida } \\
\text { útil dependendo da } \\
\text { qualidade do crédito. } \\
\text { - LGD: estimativa do } \\
\text { valor de perda. } \\
\text { - EL: baseado na EAD e } \\
\text { inclui serviços } \\
\text { inutilizados e } \\
\text { contingentes. }\end{array}$ & $\begin{array}{l}\text { - Probabilidade de } \\
\text { inadimplência do } \\
\text { crédito concedido } \\
\text { (PD). } \\
\text { - Percentual de perdas } \\
\text { no instante da possível } \\
\text { inadimplência (LGD). } \\
\text { - Exposição no instante } \\
\text { da possível } \\
\text { inadimplência (EAD). }\end{array}$ \\
\hline
\end{tabular}

Fonte: Elaborado pelos autores com base em análise das normas: Resolução n. 2.682/99, IFRS 9 e Basileia II.

Diante das comparações, vemos que a Resolução n. 2.682/99 tem os próprios critérios de mensuração e classificação para perdas, que diferem dos padrões atuais acordados pela Basileia, porém o Bacen regulamenta os aspectos da Basileia, para que as instituições financeiras estejam aderentes ao Bank for International Settlements (BIS).

Como os bancos nacionais têm liberdade para elaborar seus modelos internos de risco de crédito, acabam convergindo para as exigências do Acordo da Basileia, adotando as mesmas premissas de entrada de dados, tais como classificação interna do cliente, probabilidade de default, mitigadores de risco e maturidade das operações, além de incorporarem a taxa de recuperação de créditos vencidos e o potencial de perdas de limites de crédito concedidos e não utilizados. Dessa forma, pode-se afirmar que o sistema fi- 
nanceiro brasileiro não apresentaria muita dificuldade para se enquadrar nos critérios da norma internacional.

Com base nas análises, são apresentados os seguintes argumentos que justificam o alinhamento entre as normas:

1) A IFRS 9 está alinhada com a Basileia, demonstrando maior conservadorismo por determinar a metodologia que deve ser aplicada na classificação e mensuração das perdas. Por sua vez, a Resolução n. 2.682/99 é subjetiva ao apresentar os critérios a serem utilizados, mas não estabelece a combinação entre eles, proporcionando certa liberdade para as instituições desenvolverem seus modelos de risco internos. A IFRS atende mais adequadamente aos requisitos de risco de crédito previsto no Acordo da Basileia, o que pode ser entendido como uma evidência de maior qualidade desse padrão normativo.

2) Apesar de não determinar a mensuração e classificação das perdas segundo os padrões da Basileia, o Bacen estabelece sua adoção para as projeções de risco de crédito, e isso faz com que as instituições já abordem em suas metodologias internas os conceitos e critérios estabelecidos pelo acordo. Com isso, julgamos que o alinhamento das metodologias proporcionará o desenvolvimento de modelos internos mais robustos e específicos pelas instituições financeiras, além de reduzir os custos.

3) Como exposto no início do trabalho, a divergência entre as normas faz com que as instituições financeiras percam em custo-benefício no momento de elaborarem as suas demonstrações financeiras, pois precisam produzir informações diferentes partindo de uma única base, manter diversos controles, realizar cálculos diferentes, investir em processos onerosos e morosos, e realizar ajustes contábeis que muitas vezes atrasam as publicações para que possam atender a diferentes reguladores. Dessa forma, julgamos que o alinhamento entre as normas trará maior benefício às instituições financeiras, que poderão elaborar e apresentar seus dados sobre risco de crédito e perdas esperadas em um padrão único, garantindo maior controle e confiabilidade das informações, além da possível redução em ajustes contábeis e em custos e processos. 


\section{CONSIDERAÇÕES FINAIS}

O objetivo do trabalho foi analisar a convergência entre a nova norma IFRS 9 Instrumentos Financeiros e a Resolução n. 2.682/99, no que se refere a valor recuperável dos ativos, a fim de identificar argumentos que possam ser usados para defender o alinhamento entre elas. As análises mostram que ambas estão alinhadas aos padrões e às metodologias de risco estabelecidos pelo Acordo da Basileia e destacam que a nova norma internacional é mais conservadora que a norma local, pois estabelece métodos específicos para classificação e mensuração dos riscos e perdas, enquanto os critérios vigentes no Brasil são subjetivos e dão às entidades certa liberdade para que possam desenvolver seus modelos internos de risco de crédito. Para futuras pesquisas, recomenda-se estudar os impactos nas instituições financeiras quanto às dificuldades para implementação do modelo de perda esperada de crédito, segundo modelos da IFRS 9.

\section{IMPAIRMENT AND PCLD: CONVERGENCE BETWEEN IFRS 9 AND RESOLUTION N. 2682/99 (BACEN)}

\section{ABSTRACT}

This paper presents the comparison between IFRS 9 Financial Instruments and CMN Resolution n. 2682/99 (Bacen), in relation to impairment losses on financial assets. With the objective of proposing to regulators an adjustment to the national standard, in order to align with the international standards and to elaborate arguments that justify this alignment or the adoption of IFRS 9 by the Central Bank of Brazil, an exploratory research was conducted with documentary analysis. The results showed that both are in line with the risk standards and methodologies established by the Basle Accord, and pointed out that IFRS 9 is more conservative because it establishes specific methods for classification and measurement of risks and losses, while the criteria in force in Brazil are giving the individual certain freedom in developing their internal models. Alignment addresses different regulators, improves control and reliability of information, and reduces costs and accounting adjustments.

\section{KEYWORDS}

Convergence. IFRS 9. Impairment. PCLD. Resolution n. 2682/99. 


\section{REFERÊNCIAS}

BALDWIN, R.; CAVE, M. Understanding regulation: theory, strategy, and practice. Oxford: Oxford University Press, 1999.

BALLEISEN, E. J.; MOSS, D. A. (org.). Government and markets: toward a new theory of regulation. Cambridge: Cambridge University Press, 2010.

BANCO CENTRAL DO BRASIL. Resolução CMN n. 2.682, de 21 de dezembro de 1999. Disponível em: http://www.bcb.gov.br/pre/normativos/busca/normativo.asp?tipo=res\&ano=1999\&numero=2682. Acesso em: 16 jun. 2015.

BANCO CENTRAL DO BRASIL. Resolução CMN n. 3.786, de 24 de setembro de 2009. Disponível em: https://www.bcb.gov.br/estabilidadefinanceira/exibenormativo?tipo=Resolu\%C3\%A7\%C3\%A3o\&numero=3786. Acesso em: 16 jun. 2015.

BANCO CENTRAL DO BRASIL. Resolução n. 4.193, de $1^{\circ}$ de março de 2013. Disponível em: http://www.bcb.gov.br/pre/normativos/busca/normativo.asp?tipo=res\&ano=2013\&numero=4193. Acesso em: 5 dez. 2015.

BANCO CENTRAL DO BRASIL. Circular n. 3.648, de 4 de março de 2013. Disponível em: http://www.bcb.gov.br/pre/normativos/busca/normativo.asp?tipo=circ\&ano=2013\&numero=3648\&r=1. Acesso em: 5 dez. 2015.

BANCO CENTRAL DO BRASIL. Disponível em: http://www.bcb.gov.br/pt-br/paginas/default.aspx. Acesso em: 16 jun. 2015.

BANK FOR INTERNATIONAL SETTLEMENTS. Disponível em: https://www.bis.org/. Acesso em: 16 nov. 2015.

BASEL COMMITTEE ON BANKING SUPERVISION. Basel II: international convergence of capital measurement and capital standards: a revised framework. Basel: Basel Committee Publication, 2004. Disponível: http://www.bis.org/publ/bcbs107.htm. Acesso em: 16 nov. 2015.

BASEL COMMITTEE ON BANKING SUPERVISION. Basel II: international convergence of capital measurement and capital standards: a revised framework - comprehensive version. Basel: Basel Committee Publication, 2006. Disponível em: https:/www.bis.org/publ/ bcbs128.htm. Acesso em: 16 nov. 2015. 
BASEL COMMITTEE ON BANKING SUPERVISION. Basel III: international regulatory framework for banks (Basel III). Basel: Basel Committee Publication, 2011. Disponível em: https://www.bis.org/bcbs/basel3.htm?m=3\%7C14\%7C572. Acesso em: 16 nov. 2015.

BEAVER, W. H. Financial reporting: an accounting revolution. 3rd ed. New Jersey: Prentice Hall, 1998.

BEUREN, I. M.; RAUPP, F. M. Metodologia da pesquisa aplicável às ciências sociais. In: BEUREN, I. M. (org.). Como elaborar trabalhos monográficos em contabilidade: teoria e prática. São Paulo: Atlas, 2003.

CARDOSO, R. L. et al. Regulação da contabilidade: teorias e análise da convergência dos padrões contábeis brasileiros aos FRS. Revista de Administração Pública, Rio de Janeiro, v. 43, n. 4, p. 773-799, jul./ago. 2009.

CASCIONE, F. de S. A. Teoria da regulação francesa e o sistema financeiro nacional. 2011. Dissertação (Mestrado em Direito Político e Econômico) - Universidade Presbiteriana Mackenzie, São Paulo, 2011.

CONSELHO FEDERAL DE CONTABILIDADE. Resolução CFC n. 1.055, de 7 de outubro de 2005. Cria o COMITÊ DE PRONUNCIAMENTOS CONTÁBEIS - (CPC), e dá outras providências. Disponível em: www.cfc.org.br/sisweb/sre/docs/RES_1055.doc. Acesso em: 16 jun. 2015.

DEEGAN, C.; UNERMAN, J. Financial accounting theory. 2nd ed. London: McGraw-Hill, 2011.

GIL, A. C. Métodos e técnicas de pesquisa social. 5. ed. São Paulo: Atlas, 1999.

HERBST, K. K.; DUARTE, F. C. A nova regulação do sistema financeiro face à crise econômica mundial de 2008. Revista de Direito Econômico e Socioambiental, Curitiba, v. 4, n. 2, p. 16-38, jul./dez. 2013.

INTERNATIONAL FINANCIAL REPORTING STANDARD. IAS 39: Financial Instruments: recognition and measurement. Disponível em: http://eifrs.ifrs.org/eifrs/ViewContent?num=39\&fn=IAS39o_2005-08-18_en 4.html\&collection=2015_Blue_Book. Acesso em: $1^{\circ}$ jun. 2015.

INTERNATIONAL FINANCIAL REPORTING STANDARD. IFRS 9: Financial Instruments. Disponível em: http://eifrs.ifrs.org/eifrs/ViewContent?num=9\&fn=IFRS09o_2014-0701_en-4.html\&collection=2015_Red_Book. Acesso em: 1º jun. 2015. 
INTERNATIONAL FINANCIAL REPORTING STANDARD. Disponível em: http://www. ifrs.org/Pages/default.aspx. Acesso em: 16 jun. 2015.

MARTINS, G. de A.; THEÓPHILO, C. R. Metodologia da investigação científica para ciências sociais aplicadas. 2. ed. São Paulo: Atlas, 2009.

MISES, L. von. Money, credit and interest in theory of money and credit. Business cycle theory. London: Pickering \& Chatto, 2002.

OLIVEIRA, N. A. L. de; COSTA JÚNIOR, J. V.; SILVA, A. H. C. e. Regulação contábil no Brasil: uma análise dos processos de audiência pública do comitê de pronunciamentos contábeis (CPC) nos anos de 2007 a 2011. Advances in Scientific and Applied Accounting, v. 6, n. 1, p. 49-65, 2013.

RIAHI-BELKAOUI, A. Accounting theory. 5th ed. London: Thomson, 2004.

SILVA, M. A. Análise da regulação contábil: um ensaio à luz da teoria tridimensional do direito, da teoria normativa da contabilidade e do gerenciamento da informação contábil, numa perspectiva interdisciplinar. 2007. Dissertação (Mestrado em Gestão de Empresas) Fundação Getulio Vargas, Rio de Janeiro, 2007.

TANDY, P. R.; WILBURN, N. L. The academic community's participation in standard setting: submission of comment letters on SFA Nos. 1-117. Accounting Horizons, v. 10, p. 92-111, Sept. 1996.

TAVARES, M. F. N.; ANJOS, L. C. M. dos; PAULO, E. Contribuições enviadas ao IASB/FASB referentes à revisão do Draft de reconhecimento de receitas. Contextus - Revista Contemporânea de Economia e Gestão, v. 12, p. 35-63, 2014.

VERRONE, M. A. G. Basiléia II no Brasil: uma reflexão com foco na regulação bancária para risco de crédito - Resolução CMN 2.682/99. 2007. Dissertação (Mestrado em Administração) - Universidade de São Paulo, São Paulo, 2007.

VISCUSI, W. K.; VERNON, J. M.; HARRINGTON JR., J. E. Economics of regulation and antitrust. 4th ed. Cambridge: The MIT Press, 2005.

WATANABE, Sergio Henrique Eiti. Provisões para operações de crédito das instituições financeiras no Brasil: um estudo dos efeitos contábeis das alterações normativas do conselho monetário nacional, no período 1995-2005. Dissertação (Mestrado em Ciências Contábeis) - Universidade Federal do Rio de Janeiro, Rio de Janeiro, 2006. 